\title{
Modification of the embryo-maternal relationship in ewes by progesterone treatment early in the oestrous cycle
}

\author{
R. A. S. Lawson and L. P. Cahill \\ Department of Agriculture, Animal Research Institute, Werribee, Victoria 3030, Australia
}

\begin{abstract}
Summary. When $25 \mathrm{mg}$ progesterone/day were injected into ewes on Days 0-3 of the oestrous cycle, (i) the subsequent cycle was shortened by 4 days and (ii) on Day 6 such ewes provided an acceptable uterine environment for the survival of 10-day-old embryos. We suggest that exposure of the non-pregnant uterus to approximately 8 days of normal luteal concentrations of progesterone may be necessary to initiate luteolysis.
\end{abstract}

\section{Introduction}

Shortening of the ovine oestrous cycle by the administration of exogenous progesterone for several days after the onset of oestrus has been well documented (Woody, First \& Pope, 1967; Ginther, 1968, 1969; Thwaites, 1971). The degree of shortening effected is dependent upon dose and upon how early progesterone treatment is begun (Ginther, 1968, 1969; Thwaites, 1971). This effect could result from interference with the establishment and function of the corpus luteum at the ovarian or CNS level, or could operate through premature initiation of luteolytic action of the uterus.

The dependence of transferred embryos on synchronization for survival provides a system in which the physiological state of the uterus can be determined. For maximal survival, embryos must be transferred into a synchronous uterus and asynchrony of $>48 \mathrm{~h}$ is not tolerated (Moore \& Shelton, 1964; Rowson \& Moor, 1966). We have used this system to investigate the physiological state of the uterus in ewes treated with exogenous progesterone early in the oestrous cycle.

\section{Materials and Methods}

Five groups of mature Border Leicester $\times$ Merino ewes were taken from a flock in which oestrus was checked daily with the aid of vasectomized rams fitted with harnesses and crayons. The selected ewes had had at least 2 oestrous cycles of normal duration before the experiment. All ewes were run together with two vasectomized rams during the experiment and observed twice daily for service marks indicative of oestrus (Day $0=$ day of oestrus). The number of ewes in each group and their treatment was as follows: Group I (20 ewes), no treatment; Group II (18 ewes), $25 \mathrm{mg}$ progesterone in $2 \mathrm{ml}$ peanut oil were injected i.m. on Days $0,1,2$ and 3 of the cycle; Group III (12 ewes), progesterone treatment as for Group II and on Day 6 a 10-day blastocyst was transferred into the uterus of each ewe; Group IV (10 ewes), no progesterone treatment and on Day 6 a 10-day blastocyst was transferred to each ewe; and Group V (10 ewes), no progesterone treatment and on Day 10 a 10-day blastocyst was transferred to each ewe.

The 10-day blastocysts were obtained from suitably synchronized donor ewes which had been induced to superovulate and mated to fertile rams. The recovery and transfer of blastocysts were accomplished by the methods described by Rowson \& Moor (1966). Recipient ewes in Groups III, 
IV and V which had not returned to oestrus by Day 25 were slaughtered and their uteri examined to determine whether a pregnancy had become established.

Cycle lengths of ewes in Groups I and II were compared by Student's $t$ test and embryo survival rates in Groups III, IV and V were compared by $\chi^{2}$ tests.

\section{Results}

Progesterone treatment on Days $0-3$ significantly $(P<0.01)$ shortened the cycle length (mean \pm s.e.m.) of Group II ewes (13.8 \pm 0.8 days) compared to that of the untreated ewes in Group I (17.5 and \pm 0.3 days).

Embryo survival rates differed significantly $(P<0.01)$ between Groups III, IV and V: none of the asynchronously transferred blastocysts survived in Group IV while the survival rates were 7/10 in Group V and 8/12 in Group III. Of the non-pregnant ewes in Group III, 3 returned to oestrus after intervals of 14,15 and 17 days and the fourth had a regressing CL present on Day 25. The nonpregnant ewes in Groups IV and V returned to oestrus after normal intervals of 17 or 18 days.

\section{Discussion}

These experiments demonstrate that high levels of progesterone during the first 4 days of the oestrous cycle of the ewe hastened the development of the dioestrous uterus so that on Day 6 it was able to provide an environment acceptable to 10-day-old embryos. This 4-day advance in the physiological state of the uterus, as determined by embryo survival, is comparable with the 4-day shortening of the oestrous cycle following progesterone treatment early in the cycle observed in the present study and by Ginther $(1968,1969)$ and Thwaites (1971). It is apparent that the action of exogenous progesterone administered early in the oestrous cycle is mediated by the uterus which exhibits premature luteolytic activity, but maintains a normal sequence of development so that, after transfer, embryos which are sufficiently advanced can take advantage of the altered environment, prevent luteolysis and become established.

These experiments suggest how the timing of the luteolytic activity of the uterus can be precisely controlled. The progesterone dosage used $(25 \mathrm{mg} /$ day) was above the levels which have been satisfactory for the establishment of pregnancy in ovariectomized ewes (Bindon, 1970; Trounson \& Moore, 1973). However, Hecker, Bray \& Wodzicka-Tomaszewska (1974) found that $40 \mathrm{mg}$ progesterone/day on Days 0-3 produced plasma progesterone concentrations which were not greatly in excess of normal mid-cycle concentrations. If $25 \mathrm{mg}$ progesterone/day resulted in the establishment from Day 0 of progesterone concentrations similar to those that would normally exist from Day 4 onwards, then it appears that the condition leading to irreversible luteolytic activity by the uterus on Days 12-13 (Moor \& Rowson, 1966a, b) is a period of about 8 days when progesterone concentrations exceed a threshold normally reached on Day 4 . This is supported by the stepwise effect on the shortening of the cycle which is dependent on how soon before Day 4 progesterone treatment is begun (Ginther, 1968, 1969). The dosage effects reported by Thwaites (1971) suggest that the uterus is susceptible to the concentrations of progesterone as well as to the duration of treatment.

The ability of progesterone to modify the embryo-maternal relationship and timing of luteolysis could be significant in considerations of the problem of embryo wastage in sheep. It remains to be shown whether variations in the physiological range of progesterone concentrations in sheep in response to such factors as age, ovulation rate or management factors can induce asynchrony between the embryo and the uterus and result in the failure of pregnancy to become established.

We thank Mr D. Kerton for his valuable technical assistance throughout the experiment. 


\section{References}

Bindon, B.M. (1970) The role of progesterone in implantation in the sheep. Aust. J. biol. Sci. 24, 149158.

Ginther, O.J. (1968) Influence of exogenous progesterone and the uterus on ovarian activity in sheep. Endocrinology 83, 613-615.

Ginther, O.J. (1969) Length of estrus cycle and size of corpus luteum in guinea pigs and sheep treated with progesterone at different days of the estrus cycle. $\mathrm{Am}$. J. vet. Res. 30, 1975-1978.

Hecker, J.F., Bray, A.R. \& Wodzicka-Tomaszewska, M. (1974) Effect of exogenous progesterone on the ovarian cycle of ewes. J. Reprod. Fert. 36, 485, Abstr.

Moor, R.M. \& Rowson, L.E.A. (1966a) The corpus luteum of the sheep; functional relationship between the embryo and corpus luteum. J. Endocr. 34, 233239.

Moor, R.M. \& Rowson, L.E.A. (1966b) The corpus luteum of the sheep; effect of the removal of embryos on luteal function. $J$. Endocr. 34, 497-502.
Moore, N.W. \& Shelton, J.N. (1964) Egg transfer in sheep. Effect of degree of synchronization between donor and recipient, age of egg, and site of transfer on the survival of transferred eggs. J. Reprod. Fert. 7 , 145-152.

Rowson, L.E.A. \& Moor, R.M. (1966) Embryo transfer in the sheep; the significance of synchronizing oestrus in the donor and recipient animal. J. Reprod. Fert. 11, 207-212.

Thwaites, C.J. (1971) Exogenous progesterone and oestrous cycle length in the ewe. J. agric. Sci., Camb. 77, 147-149.

Trounson, A.O. \& Moore, N.W. (1973) The effect of progesterone and oestrogen on the survival of fertilized eggs in ovariectomised ewes. Aust. J. biol. Sci. 27, 511-517.

Woody, C.O., First, N.L. \& Pope, A.L. (1967) Effect of exogenous progesterone on estrous cycle length. $J$. Anim. Sci. 26, 139-141.

Received 1 October 1982 